\title{
Turismo e paisagem cultural: um estudo de caso de São Thomé das Letras em Minas Gerais, Brasil
}

\author{
Tourism and cultural landscape: a case study of São Thomé das Letras in Minas Gerais, Brazil \\ Turismo y paisaje cultural: un estudio de caso de São Thomé das Letras en Minas Gerais, Brasil
}

Fernanda Cristine Zamarco

Instituto Federal de Educação, Ciência e Tecnologia de São

DOI: https://doi.org/10.18472/cvt.19n1.2019.1527

Redalyc: http://www.redalyc.org/articulo.oa?

Paulo (IFSP), Brasil

id $=115459473001$

ferzamarco@gmail.com

Ricardo Lanzarini

Universidade Federal do Rio Grande do Norte (UFRN),

Brasil

ricardolanzarini@gmail.com

\section{Resumo:}

A paisagem é constituída por elementos históricos e culturais que indicam as intervenções e interações de grupos sociais ao longo do tempo. O turismo utiliza a paisagem como atração natural e cultural para o desenvolvimento de seu mercado e consequente conservação do lugar, agregando valor ao destino por seu diferencial natural e/ou histórico-cultural. Diante desse fato, analisou-se a paisagem cultural de São Thomé das Letras/MG por meio de um estudo de caso de caráter qualitativo e descritivo, utilizandose a observação participante com entrevistas semiestruturadas aplicadas a turistas, empresários e Poder Público municipal no ano de 2016. Os resultados demonstraram que essa paisagem possui diversos recursos turísticos que poderiam ser desenvolvidos como atrativos culturais para integrar um novo roteiro urbano, mas a falta de iniciativa privada e pública sobre a divulgação e utilização turística desses bens, bem como o foco nos roteiros de turismo de natureza, tem afetado diretamente o interesse dos visitantes em conhecer e apreciar a paisagem cultural local, constantemente negligenciada em sua história, representatividade cultural e conservação.

Palavras-chave: Turismo, Paisagem cultural, São Thomé das Letras.

\section{Abstract:}

The landscape is made up of historical and cultural elements that display an interference and interaction of social groups over time. Tourism taps into the landscape as a natural and cultural attraction for the development of its market and, thus, the conservation of this place, aggregating more value to this destination for its natural and/or historical/cultural uniqueness. Henceforth, it's been analyzed the cultural landscape of São Thomé das Letras/MG by a qualitative and descriptive case study, making use a participative observation with semi-structured interviews applied to tourists, entrepreneurs and the municipal public authorities in 2016's. The results displayed that this landscape possesses various touristic resources that could be developed as cultural attractives in order to integrate a new urban itinerary, but the lack of private and public initiative over the touristic use of these assets, as well as the focus on the outdoor, nature itinerary, has directly affected the visitors' interest in meeting and enjoying the local cultural landscape that is neglected in its history, cultural importance and conservation.

KEYWORDS: Tourism, Cultural Landscape, São Thomé das Letras.

\section{RESUMEN:}

El paisaje está formado por elementos históricos y culturales que muestran una interferencia e interacción de grupos sociales al largo del tiempo. El turismo aprovecha el paisaje como un atractivo natural y cultural para el desarrollo de su mercado y, por lo tanto, la conservación de este lugar, agregando más valor a este destino por su singularidad natural y/o histórica/cultural. Delante de esto, se ha analizado el paisaje cultural de São Thomé das Letras/MG por medio de un estudio de caso de carácter cualitativo y descriptivo, haciendo uso de la observación participativa con entrevistas semiestructuradas aplicadas a turistas, empresarios y las autoridades públicas municipales en 2016. Los resultados han mostrado que este paisaje posee varios recursos turísticos que 
podrían desarrollarse como atractivos culturales para integrar una nueva ruta urbano, pero la falta de iniciativa privada y pública sobre la divulgación y el uso turístico de estos recursos, así como el enfoque en el itinerario de naturaleza al aire libre, ha afectado directamente el interés de los visitantes en conocer y disfrutar el paisaje cultural local, constantemente descuidado en su historia, representatividad cultural y conservación.

Palabras clave: Turismo, Paisaje cultural, São Thomé das Letras.

\section{INTRODUÇÃO}

Paisagem e cultura são dois importantes temas de abordagem para o desenvolvimento do Turismo Cultural. No Brasil, entretanto, esse processo se iniciou a partir da década de 1990, quando a ideia do desenvolvimento sustentável passou a propor, ao turismo brasileiro, alternativas de aproveitamento de recursos renováveis. Posteriormente, diversos documentos e diretrizes seguidas por países do mundo todo passaram a apontar o Turismo Cultural como uma alternativa para o aproveitamento de recursos renováveis, além do fato de o turismo poder garantir a manutenção dos bens históricos como uma forma de autoconservação pelo uso e gestão responsável do bem, como acontece em diversos sítios históricos do Brasil que hoje são destinos turísticos consolidados, como as cidades históricas do estado de Minas Gerais, Pernambuco, Bahia, entre outras.

A cultura é resultante dos processos históricos das gerações passadas e manifestada tanto de forma imaterial (códigos, normas, costumes, crenças, linguagem, etc.) quanto material (construções, objetos, utensílios, registros escritos, etc.) que formam o que denominamos de paisagem cultural, resultante do processo social.

Compreender o processo de formação da paisagem cultural, bem como seu aproveitamento cotidiano, não é tarefa fácil, especialmente porque cada lugar possui sua particularidade: os cenários são únicos. Sobre o estudo da paisagem cultural, autores como Urry (1996) e Claval (2007) apontam a transformação dos lugares com base na dinâmica social e econômica que desenha geograficamente os lugares a partir da interação (social e econômica) de seus habitantes com a natureza e os visitantes.

As viagens sempre tiveram a contemplação da paisagem como uma de suas principais motivações, hoje, amplamente transformada em mercadoria a ser consumida por turistas. De acordo com Panosso Netto (2009) e Trigo (2013), o turista tem, naturalmente, o desejo por experiências transformadoras e autênticas, buscando sempre o diferencial de cada lugar, o novo e o exótico. Ocorre, então, uma valorização da cultura e da paisagem pela atividade turística, que usufrui daquilo que para o residente pode ser banal, mas que é inusitado para o turista.

São Thomé das Letras (STL), lugar turístico central nessa discussão, é um município brasileiro localizado na Serra de São Thomé, no sul do estado de Minas Gerais, Brasil, com população estimada de 7.106 habitantes (IBGE, 2017). Possui um extenso patrimônio natural formado por cachoeiras, nascentes e grutas que abrigam sítios arqueológicos com inscrições rupestres, fato que sempre garantiu visitantes ao município, historicamente baseado em turismo de natureza. Suas principais atividades econômicas são a mineração (extração do quartzito ou pedra São Thomé, como é popularmente conhecida), agropecuária e o turismo. A pedra São Thomé se tornou peça fundamental para a transformação da paisagem cultural, visto que essa mineração não apenas modifica a paisagem diariamente, mas a própria cidade foi construída por um sistema de encaixe dessa pedra sem qualquer forma de amarração, fato que lhe garantiu a fama de "Cidade de Pedra". Essa rocha é característica da arquitetura local e está presente desde o calçamento das ruas até as construções históricas do período Barroco ${ }^{[1]}$, como as igrejas e casas, tendo algumas de suas construções protegidas pelo Instituto Estadual do Patrimônio Histórico e Artístico de Minas Gerais (IEPHA), a saber: o Centro Histórico Matriz de São Thomé e o Conjunto Histórico Nossa Senhora do Rosário, e apenas um tombado em âmbito municipal, o Parque Municipal Antônio Rosa.

Desde os anos de 1980, o município tem atraído visitantes em busca de lugares exóticos, especialmente advindos de grandes centros urbanos como Belo Horizonte/MG, São Paulo/SP e Rio de Janeiro/RJ. De 
acordo com Fleischer (2006), muitos dos primeiros visitantes acabaram se estabelecendo no local em busca de um estilo de vida alternativo, além de investirem no turismo com a abertura de pousadas, lojas e restaurantes. Em 1996, a cidade foi incorporada ao circuito de Ecoturismo "Circuito Turístico Vale Verde e Quedas D’água” por sua riqueza natural (sem qualquer iniciativa sobre o patrimônio cultural), pertencendo também à Estrada Real, o maior projeto turístico já realizado no estado de Minas Gerais.

Já o perfil do turista que visita STL vem mudando gradativamente, especialmente em virtude do novo acesso pavimentado e do marketing turístico que se intensificou na última década. Segundo Fleischer (2006, p. 35), até 2001, o perfil dos visitantes era de jovem entre 16 e 23 anos em busca de aventuras, mas, hoje, a cidade recebe turistas entre 27 e 60 anos, interessados em aproveitar a alimentação típica da região aliada à paisagem cultural que envolve a arquitetura em pedra e as construções barrocas, o clima bucólico, a tranquilidade e a hospitalidade que não foram alterados com o tempo.

Conforme o Ministério do Turismo do Brasil (BRASIL, 2010), a paisagem de um destino é um importante diferencial na concorrência e precisa ser aproveitado como aspecto cênico e cultural, fato que confronta, à primeira vista, o destino turístico em questão. É nessa perspectiva que se desenvolveu esta pesquisa, com objetivo de analisar a paisagem cultural de STL enquanto atração turística por meio de um estudo de caso de caráter qualitativo e descritivo, com visitação realizada durante o segundo semestre do ano de 2016. Para tanto, utilizou-se a técnica da flânerie de Benjamin (1997), por meio da observação participante e errante pelos caminhos da cidade, na condição de turistas em descoberta da paisagem, além da aplicação de entrevistas semiestruturadas ao Poder Público municipal, guias de turismo e turistas, aplicadas no período de alta temporada do referido ano.

\section{PAISAGEM E TURISMO CULTURAL EM STL}

A paisagem constitui a vivência cotidiana da humanidade, revelada por todos os sentidos do corpo, ou seja, percebida e apreendida de inúmeras formas. Dollfus (1991) as classifica em: naturais, que não sofreram recentemente ação antrópica; modificadas pela ação humana, a exemplo das queimadas; e organizadas, submetidas a intervenções planejadas do homem sobre os aspectos naturais. Segundo Santos (1997), ela é uma expressão materializada do espaço geográfico, "o conjunto de formas, que em um dado momento, exprime as heranças que representam as sucessivas relações localizadas entre o homem e a natureza" (SANTOS,1997, p. 38).

A apreensão da paisagem é, nesse sentido, composta de um conjunto de fatores ambientais e humanos que determinam sua identidade e seu valor social, cultural e turístico. Bertrand (1978 apud PANOSSO NETTO, 2009, p. 46) levanta três elementos principais na definição de paisagem, a saber: o espaço material (a base da paisagem), o observador (indivíduo) e a percepção (mecanismo que cada um usa para apreender aquilo do que vê). Logo, cada paisagem é percebida de diferentes maneiras pelos turistas, gerando ou não satisfação por oferecer elementos únicos de um lugar. Ao apreciar uma paisagem, o turista pode contemplar sua beleza cênica, bem como interpretar as marcas do tempo de forma que isso lhe agregue experiências durante a viagem.

Cosgrove e Daniels (2000), ao tratar das relações entre a representação simbólica e os usos de lugares históricos, destacam que a paisagem é uma imagem cultural, o meio de representar ou estruturar simbolicamente os lugares. Andriolo (2016) aponta, ainda, que o entendimento das paisagens envolve basicamente três elementos: o simbólico (que contempla a representatividade cultural permeada pelo cotidiano), o iconográfico (que marca os lugares e lhes dá identidade, como paisagens de postais turísticos) e o ambiente geográfico (que inclui as características físicas e climáticas do lugar).

Ao reportar-se à noção de paisagem cultural, tema central desta análise, é importante retomar o conceito de cultura de Edward Tylor, que "inclui conhecimentos, crenças, arte, moral, leis, costumes ou qualquer outra capacidade ou hábitos adquiridos pelo homem como membro de uma sociedade." (LARAIA, 2003, p. 25).E é a partir da valorização da cultura tradicional que o Ministério do Turismo do Brasil afirma que o Turismo 
Cultural contempla "as atividades turísticas relacionadas à vivência do conjunto de elementos significativos do patrimônio histórico e cultural e dos eventos culturais, valorizando e promovendo os bens materiais e imateriais da cultura" (BRASIL, 2006, p. 15). Dadas suas motivações de viagem culturais mais comuns, esse segmento se subdivide em: cívico, religioso, étnico, cinematográfico, arqueológico, gastronômico, enoturismo, ferroviário e místico/esotérico, sendo que, no caso de STL, o turismo místico e esotérico tem expressivo destaque, visto que é um local de peregrinações alternativas, em busca de equilíbrio espiritual e autoconhecimento, além de ter manifestada em seu folclore, diversas lendas místicas, a exemplo de uma suposta ligação subterrânea com a cidade peruana de Machu Picchu e a aparição de óvnis e seres elementais, como duendes, fadas e gnomos ${ }^{[2]}$. De acordo com D’Auria (2000), o ambiente místico da cidade estabeleceuse na década de 1970 com a chegada de integrantes do movimento hippie no município vizinho de Três Corações/MG para o evento "Festival do Som". Também nessa época, a cidade já chamava atenção de ufólogos de vários estados brasileiros, que a consideravam um "portal de entrada no cosmos".

Em relação ao Turismo Cultural, Figueiredo (2005, p. 46) ressalta que:

Entre as modalidades de turismo existentes, o Turismo Cultural aparece como uma das estratégias de desenvolvimento sustentável, na medida em que há uma preocupação em aliar desenvolvimento econômico com a melhoria da qualidade de vida, saúde, emprego, segurança, preservação do meio ambiente e o respeito à diversidade.

O patrimônio cultural, utilizado nos destinos turísticos como atração, é regido internacionalmente pela Organização das Nações Unidas para a Educação, Ciência e Cultura (Unesco) e, nacionalmente, pelo Instituto do Patrimônio Histórico e Artístico Nacional (Iphan), podendo ser dividido em: a) material, que é constituído de bens culturais móveis (coleções arqueológicas, acervos museológicos, documentais, bibliográficos, arquivísticos, videográficos, fotográficos e cinematográficos) e bens imóveis (núcleos urbanos, sítios arqueológicos e paisagísticos e bens individuais), tendo no tombamento seu instrumento de salvaguarda; b) imaterial, que consiste nas expressões de vida e tradições transmitidas de geração em geração, sua interação com a natureza e sua história, gerando um sentimento de identidade, salvaguardado pelo registro dos bens culturais de natureza imaterial.

A paisagem cultural ilustra a trajetória histórica da sociedade humana em seu ambiente, de acordo com sua produção espacial, social, cultural e econômica. O Conselho Internacional de Monumentos e Sítios (Icomos), ligado à Unesco, a divide em três categorias: a) paisagem claramente definida, que envolve jardins e parques criados propositalmente, por motivos predominantemente estéticos; b) paisagem evoluída organicamente, que resulta da interação inicial de ordem social, econômica, administrativa e/ou religiosa com o ambiente natural; e, c) paisagem cultural associativa, que se justifica pelas associações religiosas, artísticas ou culturais com o elemento natural, sem a evidência material da cultura, que pode ser insignificante ou ausente (IPHAN, 2010).

Conforme o MTur (BRASIL, 2010), o desenvolvimento do Turismo Cultural, aliado à conservação do patrimônio e à paisagem cultural, é capaz de integrar as características do ambiente cultural, como a matériaprima da região, a mão de obra local e a adaptação de imóveis históricos para uso turístico, valorizando-o. Atualmente, STL é também conhecida como "Cidade Mística”, sendo o esoterismo um atrativo turístico para pessoas que buscam um encontro com o meio natural associado ao bem-estar espiritual. Tuan (1980) destaca que o orgulho cívico e a concorrência econômica frequentemente associam-se para dar rótulos às cidades e destacar seu diferencial ante as demais cidades turísticas, usando determinados slogans para despertar o interesse do turista em visitar o local.

A paisagem de STL vem sendo modificada desde o final do século XVIII devido às ações antrópicas relacionadas ao extrativismo mineral do quartzito. Ainda hoje, a mineração é realizada de forma rudimentar em muitas empresas, com processos de modernização ocorrendo em outras (CHIODI, 2003). A população local diariamente utiliza sistemas irracionais de exploração do solo, deteriorando o ecossistema. (FERRETTI, 2002, p. 82). Segundo Fleischer (2006), com a falta de tecnologia aplicada, as mineradoras locais extraem 
pedras somente próximas à superfície. Assim, as jazidas avançam horizontalmente, ocupando cada vez mais área de mata nativa.

Tuan (1980) destaca que as mudanças na paisagem refletem as mudanças tecnológicas, a economia e a atitude das pessoas sobre o que desejam de seu meio ambiente físico. STL passa por uma constante transformação ocasionada, principalmente, pela vinda de turistas que fixaram residência no local e pelos efeitos danosos da mineração. A cidade tem um estilo único presente em sua arquitetura, com a edificação de igrejas, casas e casarios em pedra encaixada (sem o uso de argamassa) que datam do final do século XVIII. Atualmente, esses espaços abrigam pousadas, lojas e restaurantes que servem aos turistas, sustentando parte do patrimônio arquitetônico local. Para Azevedo, Mattos e Bartholo (2015, p. 261), "o estímulo à visitação de lugares/sítios históricos através de atividades culturais para diferentes públicos pode servir de veículos mobilizadores da sociedade contribuindo para a integração de políticas públicas de cultura e turismo”.

Caminhar pelas ruas de uma cidade histórica, podendo prestar atenção a cada detalhe da paisagem, a cada casario que surge pelo caminho e às representações do cotidiano, é, certamente, uma descoberta prazerosa e individual. STL revela, a cada esquina, algo de encantador e inusitado, ligado ao seu cenário místico e à presença da mineração, além da arquitetura em pedra. É bastante comum encontrar, ao longo do caminho, referenciais ligados ao sobrenatural (bruxas, magos, ETs., duendes, óvnis), sejam presentes no artesanato, no vestuário, no estilo de vida hippie dos moradores e turistas, ou nomeando e decorando estabelecimentos comerciais e meios de hospedagem. De acordo com o Inventário de Proteção ao Acervo Cultural de São Thomé das Letras, os bens tombados são: Centro Histórico Matriz de São Thomé, Conjunto Histórico Nossa Senhora do Rosário e o Parque Municipal Antônio Rosa, compondo os mais importantes pontos de visitação da cidade.

Em busca de compreender como se dava a organização turística e o uso dos bens culturais no município, foi entrevistada a chefe do Departamento de Cultura e Proteção do Patrimônio Histórico e Artístico de STL (Entrevistada-1), que descreve a atividade turística como uma importante fonte de renda para os moradores locais (que basicamente vivem da mineração), seja como renda principal ou segunda renda, até porque são poucas as oportunidades de trabalho, especialmente para o mais jovens. Expõe que os Departamentos de Turismo e de Cultura são separados em STL, estando o de Turismo há alguns meses sem chefia, sendo operante apenas o Conselho Municipal de Turismo (Comtur).

No ano 2000 foi implementado o Conselho Municipal do Patrimônio Histórico e Artístico de STL (Comphast), cujo papel fundamental é garantir a proteção do patrimônio material. Entre suas ações, incentiva diversos eventos culturais, como o tradicional Encontro de Folias de Reis, o Carnaval, o Festival da Canção local e o Festival Nacional da Canção (Fenac), a Festa da Colheita (Festa de Agosto), entre outros. Sobre esse uso dos bens culturais, a Entrevistada-1 (E1) cita o exemplo de um evento chamado "Pôr do Rock" que ocorria no Parque Municipal Antônio Rosa, na Casa da Pirâmide.

\footnotetext{
Esse evento era de apresentações musicais e, como acontecia dentro do parque, deveria ser autorizado pelo Comphast, mas não é habitual por aqui perdir permissão para as coisas, até porque aquela é uma área particular. Um dia recebeu-se uma denúncia de que eles queriam cimentar uma parte das pedras para facilitar a colocação dos instrumentos musicais e, desde então, o Comphast embargou o evento. [...] Queremos eventos culturais sem a alteração do patrimônio, com o mínimo de impacto (E1, 2016).
}

E1 se remete às questões da sustentabilidade no desenvolvimento dos destinos turísticos e o uso dos bens patrimoniais, pois a ampliação do fluxo de turistas pode trazer inúmeros prejuízos ao patrimônio quando este não é devidamente protegido e administrado. Em adição, ela define STL como um mosaico, com grande diversidade de oferta turística e de público, mas com pouco incentivo à cultura.

As construções exóticas para nós que moramos aqui são parte do cotidiano, mas o visitante acha bem diferente o calçamento de pedra, as casas [...]. O patrimônio ajuda, sim, a trazer o turista, embora a maioria das pessoas venha por conta dos atrativos naturais, das cachoeiras, grutas, trilhas, etc. Há poucos guias que fazem roteiros na cidade e é raro aqueles que têm informações sobre os patrimônios. Pensamos em fazer uma parceria com o Departamento de Turismo para que os guias recebessem o 
treinamento adequado, conhecendo a história de São Thomé, suas lendas e dados históricos dos patrimônios tombados, mas isso ainda não aconteceu. [...] Há muita desinformação entre os moradores, guias e a própria Prefeitura, que também repassa informações equivocadas em algumas placas turísticas. Muita coisa precisa ser revista! [...] Alguns guias oferecem informações históricas porque fazem um roteiro mais esotérico, levando o turista até os pontos energéticos e, por isso, sabem contar as lendas e dar esse ar místico à cidade $(\mathrm{E} 1,2016)$.

Já o Entrevistado-2 (E2) é guia de turismo local. Ao ser questionado sobre quais atrações o turista tem mais interesse em visitar, os roteiros trabalhados e qualificações que recebem para os aspectos culturais, ele ressaltou que os turistas visitam STL primeiramente pelos atrativos naturais e "[...] somente estando aqui que os turistas verificam que os atrativos culturais são tão bonitos e intensos que valem ser conhecidos. Mas isso se deve à divulgação que é feita sobre a cidade, sempre focada nos atrativos naturais” (E2, 2016). Expõe que o município possui bens tombados que representam um grande atrativo cultural, mas o uso turístico é desordenado.

Talvez existam somente umas três pessoas que trabalham com este material na cidade (city tour) mostrando os atrativos culturais. [...] Os turistas sempre comentam sobre as belezas e as necessidades da cidade, mas, como não existe uma política voltada para o turismo, as necessidades são as mesmas de sempre e não se tem um trabalho direcionado para solucioná-las. Ajudei a fundar a Associação de Guias na cidade com esse objetivo. Contudo, há pouco interesse em se capacitarem nesse aspecto. Hoje a Associação está montando um curso de bens patrimoniais e já me prontifiquei em montar um curso para se elaborar um citytour (místico, esotérico, religioso, cultural e patrimonial), mas também houve pouco interesse. A cidade tem um potencial incrível e poucos lugares do Brasil têm tanto material como STL, mas, como falei, não existe interesse do poder público em desenvolver esse aspecto (E2, 2016).

Fica evidente nas falas de E1 e E2 que falta iniciativa e apoio por parte do Poder Público em incentivar o Turismo Cultural, que deve começar com a conscientização e sensibilização do trade turístico para o aproveitamento responsável do patrimônio no mercado turístico, visto que esse seria o papel do Departamento Municipal de Turismo que, durante a pesquisa, mostrou-se ineficiente. Logo, a expansão do turismo no município tem se dado apenas pelo interesse da iniciativa privada na comercialização dos bens naturais, perpetuando o velho modelo de desenvolvimento do turismo dos anos de 1980, desordenado e amador.

Nos dias de hoje, são encontrados restaurantes japoneses, churrascarias, creperias, cafés, pizzarias, campings, hostels e pousadas com piscina aquecida e café da manhã com especiarias típicas, passeios turísticos e atividades de lazer, como eventos culturais, competições de enduro e mountain biking, passeios ciclísticos e vários pontos para a prática de esportes radicais. A gastronomia local apresenta pratos típicos da culinária mineira. Os restaurantes típicos servem diariamente suas especialidades, como o frango com polenta, vaca atolada, tutu de feijão e a carne de porco na lata, conservada na própria gordura. Bares e casas noturnas garantem o entretenimento noturno. Quase tudo se concentra em torno da praça central, em frente à Igreja Matriz.

\section{CAMINHANDO POR SÃO THOMÉ DAS LETRAS}

Caminhar pelas ruas de pedra, perceber os detalhes das antigas construções e conversar com moradores e turistas é uma experiência única em STL. As principais atrações histórico-culturais da cidade são o Centro Histórico Matriz de São Thomé, que inclui igreja e gruta; o Conjunto Arquitetônico Nossa Senhora do Rosário, composto pela igreja de pedra e a praça circundante; e o Parque Municipal Antônio Rosa, que tem a Casa da Pirâmide, Cruzeiro, Pedra da Bruxa, Mirante, Toca do Leão e o Caminho do Peregrino.

Durante sete dias consecutivos, ao longo do mês de julho de 2016, percorreu-se cada um desses atrativos a fim de experienciar a condição de turista em busca da vivência cultural, da identidade e da aproximação entre turistas e residentes em STL, compreendendo o lugar turístico como um estudo de caso, por meio da pesquisa participante, na condição de turista, em busca de experiências significativas. O estudo de caso, enquanto 
método de pesquisa, é descrito por Yin (2015) como uma necessidade de compreensão dos fenômenos sociais complexos que "permite que os investigadores foquem um 'caso' e retenham uma perspectiva holística e do mundo real” (YIN, 2015, p. 4).

Para tanto, utilizou-se a técnica da flânerie de Benjamin (1997), em que foi possível circular pelos espaços anonimamente, na condição de turista, e observar outros turistas e os residentes, os bens e a forma como são apresentados para o turista. A observação participante, de caráter qualitativo e descritivo, é uma técnica em que o pesquisador se coloca na condição do objeto pesquisado e dele faz parte (RICHARDSON, 1999). Ao longo desse processo, foram aplicadas algumas entrevistas com visitantes desses locais, selecionados a partir da observação e da aproximação entre pesquisadores e visitantes, visto que é bastante comum identificar no rosto do turista a surpresa em ver um patrimônio que não imaginava encontrar, a peculiaridade da arquitetura local e a beleza cênica da paisagem natural e cultural. Conforme Lima (2016, p. 27), na entrevista "é possível construir histórias de vida, captar experiências, valores, opiniões, aspirações e motivações dos entrevistados, escolhidos segundo os critérios e interesses do tema investigado".

O primeiro contato visual que se tem de STL é a imagem de uma pequena cidade que foi cuidadosamente esculpida sobre uma montanha. De longe, já era possível identificar uma paisagem esbranquiçada, as pilhas de rejeitos de pedra deixadas pelas mineradoras pareciam fazer parte do ambiente. Porém, mais de perto, a verdade já se revelava assustadora: a extração de pedra parecia engolir a cidade, trazendo um aspecto de destruição hollywoodiana. Logo na entrada da cidade, há um pórtico e a estátua de São Thomé, ambos bastante deteriorados pelo tempo e pela pichação de vândalos.

Ao adentrar na cidade, a sensação é de se ter voltado no tempo, de estar em uma atmosfera completamente diferente do habitual no Brasil, com uma arquitetura em pedra muito particular e pitoresca. $\mathrm{O}$ ambiente social da pequena cidade é bastante acolhedor e hospitaleiro. As casas de pedra fascinam a todos e o tempo parece não correr: há uma clara sensação de que o dia dura mais horas que o habitual. O calçamento em pedras é bastante irregular, o que dificulta qualquer forma de transporte rápido e, por esse motivo, tudo parece se movimentar em câmera lenta.

A principal via de entrada conduz ao Centro Histórico da Matriz de São Thomé, local em que há, diariamente, a maior concentração de pessoas, pois está repleto de lojas de souvenirs, restaurantes de comida típica mineira, bares e pequenas hospedarias de arquitetura em pedra. Perambulando pelo centro histórico se encontra, em uma hospedaria rústica, uma ilustração orientativa dos pontos turísticos naturais e outra do espaço urbano, enfatizando o receptivo turístico e alguns atrativos da cidade, como as igrejas, a Gruta São Thomé e até a Sociedade Brasileira de Eubiose. Esses guias impressos mencionam alguns atrativos culturais urbanos, porém, quando o turista se direciona até os locais indicados, como as igrejas, por exemplo, ele não tem acesso a informações nem a serviços de guiamento local para conhecer o atrativo. Tão pouco esse atrativo está disponível para visitação, pois as igrejas abrem apenas no horário das missas e funções religiosas. Então, o turista pode apenas fotografar seu exterior e ter uma visão superficial da paisagem cultural.

Somente a Gruta São Thomé permanece aberta, mas sem qualquer informação relevante que valorize a história do lugar. O local possui uma escada que dá acesso, no topo da gruta, a um mirante. É um dos pontos turísticos mais visitados, especialmente por sua localização ao lado da Igreja Matriz, concentrando um expressivo movimento de turistas. Nesse atrativo foram realizadas as duas primeiras entrevistas com turistas.

A Entrevistada-3 (E3) salientou frequentar STL há três anos, pretendendo, desta vez, permanecer por um mês. Ao questioná-la sobre a paisagem cultural local, expõe que:

A paisagem cultural da cidade é bem conservada, mas ao mesmo tempo ela ainda está sofrendo muitas adaptações. Creio que falte incentivo da própria população e dos governantes da cidade: às vezes quem faz mais coisas são as pessoas que vêm de fora e moram aqui. Eu frequento os atrativos naturais de São Thomé porque os culturais eu sinto que nem os guias sabem direito para onde vão nos levar. [...] Não é todo mundo que sabe a história da cidade não! [...] É uma cidade que você leva uma bagagem muito forte de energia e também sai com uma visão da falta de conservação do patrimônio e da história do Brasil (E3, 2016). 
Já o Entrevistado-4 (E4) permaneceria na cidade por uma semana e se mostrou muito empolgado com a paisagem, o exótico e surpreendente encanto que o lugar proporciona aos visitantes.

Já conheci muitos lugares aqui. Desde que cheguei, foi tudo agradável, satisfatório e uma alegria total. [...] Vários amigos meus já vieram para cá, mas, dessa vez, eu vim sozinho. Eu achei o estilo arquitetônico da cidade muito bacana e espero que isso seja reconhecido mundialmente. [...] Pretendo voltar sempre e trazer várias pessoas comigo, pois todo mundo deve saber que existe um lugar tão alternativo quanto esse no Brasil $(\mathrm{E} 4,2016)$.

A Gruta São Thomé possui, ao seu redor, grades e concreto, o que descaracteriza demasiadamente sua paisagem rústica de pedra. A escada de acesso à gruta parece facilitar a entrada do visitante, mas, ao se considerar os diferentes perfis de turistas, como idosos e deficientes físicos, não há condições de acessibilidade e sua estrutura é esteticamente prejudicada pelos recursos artificiais em ferro que teoricamente foram instalados para proteção e acesso, como corrimãos.

$\mathrm{Na}$ praça central encontram-se pequenas barracas de artesanato, majoritariamente hippies, além de frequentes apresentações de artistas locais. Nesse ponto, o passeio foi feito ao som de flautas, proporcionando uma agradável sensação de bem-estar. Na sequência, encontrou-se a Entrevistada-5 (E5), que salientou seu encantamento com o clima místico do lugar, permanencendo ali por duas semanas.

Venho aqui desde 2012. Eu acho muito interessante aquela cachoeira Xangrilá que tem algumas pinturas rupestres e, além disso, gosto muito do Parque Antônio Rosa porque lá tem vários lugares para conhecer: gruta, pinturas rupestres e uma paisagem muito bonita. [...] Uma coisa que eu acho muito feia são as pedreiras: você chega à cidade e a primeira coisa que vê são as montanhas de rejeitos, aquela coisa branca horrível que podia ser cheia de árvores, uma coisa mais preservada. [...] E não posso deixar de mencionar que a cultura forte daqui é o rock, além de ser uma cidade de artistas, com muita arte nas ruas; muita gente vive disso aqui. (E5, 2016)

Para chegar até o Parque Antônio Rosa, o acesso é por degraus naturais de pedra. De lá, pode-se vislumbrar toda a vista da Serra de São Thomé, incluindo a cidade e alguns dos caminhos e trilhas para os atrativos naturais. Nessa época do ano, as temperaturas são baixas, próximas a zero grau durante a noite. Então, é bastante comum encontrar um numeroso amontoado de turistas ao entardecer e início da manhã para admirar o nascer ou o pôr do sol no teto da Casa da Pirâmide, feita totalmente em pedra. Todos que por ali apreciavam a paisagem, meditavam ou cantavam ao som do violão, com ambientação ligada à paz interior, ao místico e cênico paradisíaco. Contudo, também era possível observar algumas pedreiras e a ação de destruição que o homem causa ao meio ambiente, sendo um grave problema que destoa na paisagem.

Com outro turista que por ali repousava, Entrevistado-6 (E6), o diálogo partiu da concepção de paisagem que ele tinha e buscava naquele lugar. Era sua segunda experiência em STL, agora para ficar todo o período de férias escolares. Para ele:

A paisagem cultural é bem bacana, apesar da extração de pedra deixar a cidade mais feia do lado de fora; mas, o interior da cidade é bem preservado, muito bonito visualmente. Mas é uma pena porque as pedreiras são um aspecto muito desagradável que, com o passar do tempo, vai piorar. Até têm alguns projetos que impedem a mineração de se aproximar da cidade, mas, como não é muito monitorado, fica “a ver navios”. Eu fiquei sabendo que na estrada, sentido a cachoeira da Eubiose, tem uma nascente chamada Biquinha, e uma pedreira era responsável de cuidar dessa nascente, que seca, dependendo da estação do ano. [...] E não é muito monitorado, os donos das pedreiras são gente de fora da cidade; o pessoal daqui que trabalha são apenas funcionários. Mas, tem que ajudar a preservar também para manter para as próximas gerações. Eu quero ver a cidade como uma atração cultural e, com certeza, indico para todo mundo $(\mathrm{E} 6,2016)$.

Voltando para o centro da cidade, o destino era a Igreja Nossa Senhora do Rosário, feita integralmente em pedra por e para os escravos que habitavam a região. Esse é um dos atrativos mais procurados e fotografados e que permanece fechado durante toda a semana, sendo possível apenas contemplá-lo pelo lado de fora ou durante as missas de domingo, fato que demonstra o despreparo das autoridades locais em relação ao uso do patrimônio cultural como atração turística. Muitos turistas, ao se depararem com a impossibilidade de conhecer o interior da igreja e pela ausência de informações, acabam apenas parando para uma foto, sem qualquer ambientação com a paisagem cultural do entorno da igreja ou a história do município. 
Durante as noites, bares e restaurantes permanecem lotados. Por conta do estilo alternativo da comunidade hippie, muitos oferecem opções para veganos e vegetarianos. Os preços, se comparados à maioria dos centros turísticos no Brasil, são consideravelmente baixos. Nesse ambiente foi identificado um casal de cariocas que concedeu entrevistas. O Entrevistado-7 (E7) e a Entrevistada-8 (E8) estavam em STL pela primeira vez, com intenção de permanência de uma semana em uma casa comunitária, que corresponde ao que seria uma categoria cama e café. É hábito da comunidade hospedar turistas em suas casas como forma de renda alternativa, proporcionando-lhes uma experiência cultural ainda mais significativa. Eles relataram que:

Nós já conhecemos a gruta e o vale das borboletas. O mais interessante é o envolvimento da cidade com as pedras. Por exemplo: aquela pirâmide do alto, o cruzeiro que também é legal; e o povo daqui é muito hospitaleiro. Eu achei bem interessante aquela gruta que tem do lado da Igreja Matriz, que tem um altar para São Thomé (E7, 2016).

Não identificamos nada negativo. E nós pretendemos voltar aqui com certeza! Eu indicaria, sobretudo por um fator de valor histórico, eu acho que realmente a história da cidade e como ela é retratada nos artesanatos é bem forte $(\mathrm{E} 8,2016)$.

No decorrer dos dias, andar pelas ruas da cidade, observar as casas, a infraestrutura turística, como os bancos, postos de gasolina, supermercados e o centro de atendimento ao turista era sempre uma descoberta. Cada observação, cada detalhe, cada novo acontecimento cultural na praça marcava a flânerie. Considerandose o tamanho da cidade, a qualidade e a diversidade de serviços oferecidos aos turistas, são satisfatórios, inclusive, sendo um item atestado nas entrevistas. Outro fato marcante, mas desconfortável, é o barulho das explosões de dinamite nas pedreiras, recorrente a cada 20 minutos e que destoa do clima de tranquilidade do lugar místico.

O Entrevistado-9 (E9) foi abordado em um equipamento de restauração e comentou ter voltado a STL para relembrar seu tempo de adolescência, pois esse era seu local preferido de férias nos anos de 1980. Nessa temporada, passaria cinco dias revisitando seus lugares de memória.

Eu venho para cá visitar as cachoeiras, as grutas e estava reparando hoje, apesar de já ter vindo outras vezes, que os patrimônios da cidade estão pouco preservados. Falando em termos de marcos históricos, você vai a outras cidades de Minas e isso é muito mais marcante. Eu acho que a mineração é um aspecto bem negativo, um dia a extração de pedra vai comer a montanha inteira. O latifúndio também é absurdo aqui: todos os lugares que você vai são particulares, você olha e vê que é tudo de uma pessoa só. [...] Aqui na cidade eu não conhecia nada, eu vinha para cá, mas nunca pensei nessa questão histórica. E os guias só nos passam essa parte dos atrativos naturais. Eu indicaria a cidade como um atrativo cultural, talvez pela cultura alternativa, mas não pela questão histórica porque falta cuidado (E9, 2016).

Os guias de turismo da cidade ficam sempre com seus jipes e camionetes parados na praça da matriz aguardando os turistas, mas a procura de um guia que trabalhasse com o Turismo Cultural e tivesse informações sobre os patrimônios urbanos foi em vão. O único local que aparentava ser uma agência de turismo ficava a maior parte do tempo fechado. Durante as poucas vezes em que estava aberta, tinha apenas um atendente que contatava os guias e apresentava passeios aos atrativos naturais, mas não respondia por nada organizacional dos roteiros, nem tinha conhecimentos sobre questões históricas e culturais.

Por informações de moradores locais, soube-se que havia um guia que trabalha com city tour e que ficava na praça da Igreja Matriz, mas em nenhum dia ele foi encontrado. Então, outro guia nativo, o Entrevistado-10 (E10), discorreu sobre alguns aspectos do turismo local:

Em São Thomé as pessoas vêm, principalmente, pelos atrativos naturais: as grutas e cachoeiras, mas tem a parte mística da ladeira do amendoim, que é muito procurada, e a energia da cidade. O pessoal gosta bastante de curtir o pôr do sol, a visão que se tem aqui de cima da montanha para todo o horizonte. [...] A minha empresa não trabalha com city tour, mas têm os guias que fazem as visitas nos casarões, igrejas, os passos e a pirâmide. Isso gera uma renda. Tem um guia, que é bem preparado, tem conhecimento sobre a história do município, mas são poucos que têm um amplo conhecimento sobre os lugares e a história. [...] A paisagem cultural de São Thomé poderia ser mais aproveitada: a gente tem aqui o patrimônio imaterial, que poderia entrar como visita do city tour, tem umas festas populares do Natal até 6 de janeiro, que é a Folia de Reis, um tipo de festa que está se perdendo. [...] Dentro da cidade, esses bens materiais são pouco aproveitados, tirando alguns restaurantes que aproveitaram as fachadas dos casarões e mantêm um trabalho legal, os passos praticamente nem são visitados. Só tem quatro passos que ficam abertos na cidade: são parecidos com capelinhas, na época da construção da cidade e dos casarões 
antigos. Eram muito tradicionais, na Semana Santa, as procissões; e esses passos marcavam os passos de Cristo, onde ele foi crucificado, a via-crúcis dele. Então essas capelinhas eram ornamentadas e ficavam com Santos de devoção. A procissão parava, uma a uma, e fazia orações. Hoje, apenas quatro passos estão preservados, mas existiam 12 no total (E10, 2016).

Rendendo-se aos passeios naturais, os únicos realmente organizados com saídas diárias, aproveitou-se o contato direto com ecoturistas para aprofundar a investigação. Foi aqui que se conseguiu a última fala com a Entrevistada-11 (E11).

\begin{abstract}
Eu acho muito bonito a arquitetura das casas ser feita em cima das rochas. Essa coisa misteriosa e mística é muito gostosa. É uma cidade que vale a pena conhecer! É a primeira vez que eu venho, mas meu namorado já tinha vindo aqui várias vezes porque ele é motociclista e aqui também é o reduto do motoclube. Eu cheguei ontem e quero ficar aqui por meses porque a energia positiva que atrai é muito boa, é nítido isso! O povo em si, a humildade das pessoas; [...] é um lugar enigmático, eu recomendo! [...] Sem palavras para descrever: amei e quero vir aqui muito mais vezes. [...] Toda essa história que gira em torno do misticismo é capaz de atrair um pouco mais os turistas, principalmente jovens. E estou gostando do que estou vendo, a paisagem em si tem uma magia que nos move em torno do bem, desse sentimento do querer estar cada vez mais próximo da natureza; e isso é bom $(\mathrm{E} 12,2016)$.
\end{abstract}

Assim como a Igreja de Pedra, a Igreja Matriz permanecia fechada durante o dia, abrindo somente para as celebrações, fato que demonstra um ponto negativo na oferta de atrativos e captação de turistas que querem conhecer esses lugares. Outra atração inusitada é o cemitério aéreo que está localizado ao lado da Igreja Matriz. Anteriormente, as pessoas eram enterradas sob o assoalho da igreja e também a sua volta, no pátio, onde é possível observar diversos nomes. Segundo uma placa informativa no cemitério, devido ao solo rochoso, as sepulturas foram construídas a sete palmos acima do solo no terreno adjacente à igreja, tal qual um cemitério invertido, fato que desperta muita curiosidade nos turistas.

Todos os dias, no horário do pôr do sol, a Pirâmide fica lotada de pessoas que buscam a contemplação do horizonte, despedindo-se do sol com aplausos em agradecimentos ao "Astro-Rei" por mais um dia de luz na Terra, como um gesto simples de amor à natureza e à vida. Para completar o cenário, do lado oposto, surge a lua cheia com um tom cor-de-rosa no horizonte. Cai a noite e o frio se intensifica, mas as pessoas permanecem ali em estado de êxtase e contemplação.

Para finalizar a flânerie, foram verificados os acessos ao município que se apresentaram ineficientes. Por volta das $9 \mathrm{~h}$, a rodoviária estava fechada, sem qualquer placa informativa de horário ou funcionários trabalhando. Após uma longa espera, seguida da desistência, e sem qualquer serviço de táxi na proximidade, o retorno à hospedaria era inevitável. Foi lá que se obteve a informação de que o mais fácil seria ficar no portal da cidade (que não possui qualquer ponto de apoio ou sombra) para esperar um ônibus qualquer que passasse, ou mesmo uma carona, pois é um hábito dos moradores locais dar carona àqueles que se aventuram pela rodovia (fato que remete, mais uma vez, à cultura hippie). Nessa tentativa, em menos de 5 minutos, uma ambulância que estava descendo o morro parou para oferecer uma carona até o município mais próximo, de onde seria possível continuar a viagem.

\title{
4. CONSIDERAÇÕES FINAIS
}

São Thomé das Letras é um lugar turístico que tem ganho expressivo destaque nos últimos anos, tanto nacional quanto internacionalmente, mas é notório seu amadorismo estrutural na organização do turismo, reproduzindo, ainda, os vícios e erros brasileiros do crescimento desordenado do turismo das décadas de 1970 e 1980, o que acarreta prejuízos tanto ao patrimônio natural quanto cultural.

A cultura hippie trouxe para o lugar uma atmosfera de hospitalidade e liberdade que é única, capaz de despertar o interesse do turista em retornar e permanecer o maior tempo possível em contemplação aos atrativos, experienciando o modo de vida local. Entretanto, é inegável que faltam mais atividades culturais e esotéricas para preencher o tempo ocioso do turista. Uma estratégia eficiente seria capacitar os guias de turismo para um roteiro de visitação histórico-cultural, auxiliando na conservação dos poucos espaços de 
pedra que ainda restam, bem como para despertar na comunidade receptora o orgulho identitário por meio de campanhas sobre a história local e o incentivo aos traços culturais, como o folclore e a arte.

Tanto o Poder Público quanto o privado são responsáveis diretos pelo futuro do turismo em STL. Além da valorização do patrimônio cultural, material e imaterial, é preciso refletir sobre o modelo de turismo que se tem construído nas últimas décadas, bem como o perfil de turista que se atrai a partir desse modelo, visto que é comum encontrar parte de patrimônio pichado por turistas que gravam seus nomes e locais de procedência nas pedras e monumentos. Nesse sentido, o Turismo Cultural, tanto histórico quanto místico e esotérico, traz a perspectiva de outro cenário, com outros perfis de turistas, se comparado com o atual modelo de turismo de natureza e eventos para públicos jovens, que normalmente excedem no uso de bebidas e drogas ilícitas, além de trazerem pouco retorno financeiro à economia local.

Embora as atrações naturais sejam a principal motivação das viagens, elas se encontram, em sua maioria, fora dos limites urbanos. Já os aspectos culturais, especialmente os arquitetônicos, configuram o primeiro grande impacto visual do exótico paisagístico que se tem ao chegar em STL. Exótico porque é único, mas, também, frustrante porque é parcialmente inacessível, considerando-se que não há visitações orientadas, tão pouco informações educativas disponibilizadas ao turista. Além disso, o Turismo Cultural poderia ser uma ferramenta de controle da sazonalidade, dada a relação frágil que se constrói quando um local de grande variação climática se sustenta turisticamente apenas com base em atrativos naturais aquáticos, visto que durante o inverno brasileiro ocorre uma baixa temporada local que poderia ser amenizada com eventos culturais que, além de colaborar com o aumento do fluxo de turistas, poderia valorizar ainda mais o patrimônio cultural material e imaterial.

Todavia, não há interesse por parte dos guias de turismo em se qualificar nesse segmento. É possível que falte à população local um apreço pelo munícipio e o reconhecimento do turismo como alternativa econômica à extração de pedra. Os moradores locais parecem não compreender o diferencial histórico e arquitetônico do município e, por isso, não valorizam seus patrimônios culturais e sua identidade, visto que boa parte das iniciativas de conservação do local advém de novos moradores que trabalham no setor turístico, em contraposição aos nativos que sobrevivem da mineração. Os eventos culturais, místicos ou religiosos, como já acontece com a tradicional Procissão da Semana Santa e a Festa de Agosto, que costuma reunir cerca de 20 mil pessoas por ano, são alternativas isoladas desse viés cultural, que deveriam ser ampliadas com a captação de novos eventos, como retiros, festivais gastronômicos e musicais.

O mau funcionamento do serviço de transportes demonstra o despreparo local para atender bem e com qualidade aos turistas que, mesmo em um período de alta temporada, não têm horários regulares de transporte coletivo. Também é evidente o descaso do Poder Público com o planejamento e organização do turismo, especialmente em relação aos patrimônios culturais, que não são devidamente aproveitados e conservados. A falta de comprometimento do Poder Público implica em uma visão negativa por parte dos turistas, que não possuem outro meio de transporte a não ser o ônibus (que é bastante utilizado no Brasil, inclusive por estrangeiros) para chegar ao município. Além disso, as informações sobre o acesso veiculadas nas mídias digitais são confusas e não correspondem à realidade, o que comprova uma falta de investimentos, inclusive em atendimento aos turistas.

Outro aspecto que merece atenção no planejamento turístico é a questão da acessibilidade a portadores de deficiência ou mobilidade reduzida. Mesmo considerando-se que a estrutura em pedra historicamente não foi pensada para essa situação, como é natural em todas as cidades históricas do Brasil, é preciso remodelar os espaços principais de visitação, de modo a garantir um acesso mais inclusivo a todos.

A relação bem-sucedida entre turistas e prestadores de serviços é um referencial de qualidade do produto, fato que garante confiabilidade ao consumidor por meio da boa propaganda, especialmente aquela feita boca a boca (e deve-se considerar que foi dessa forma que o turismo chegou a STL) e a profissionalização de um modelo de turismo responsável com o meio ambiente, a cultura e os moradores locais, de modo que seja uma atividade econômica rentável e alternativa ao modelo predatório vigente. 


\section{REFERÊNCIAS}

ANDRIOLO, A. A paisagem da cidade histórica e turística: fenomenologia da experiência estética. Caderno Virtual de Turismo, v. 16, n. 3, p. 91-105, 2016.

AZEVEDO, A.; MATTOS, F.; BARTHOLO, R. Entre o espaço e o lugar: considerações sobre o Campo de Santana e a Casa de Deodoro na dinâmica cultural e turística da cidade do Rio de Janeiro. Caderno Virtual de Turismo, v. 15, n. 3, p. 251-262, 2015.

BENJAMIN, W. Obras escolhidas III - Charles Baudelaire: um lírico na época do capitalismo. Brasiliense: São Paulo, 1997.

BRASIL. Ministério do Turismo. Diretrizes para o desenvolvimento do Turismo Cultural. Brasília: Ministério do Turismo, 2007.

. Ministério do Turismo. Turismo Cultural: orientações básicas. Brasília, 2010.

. Ministério do Turismo. Segmentação do Turismo: marcos conceituais. Brasília: Ministério do Turismo, 2006.

CHIODI, D. K. Os quartzitos de São Tomé das Letras, Minas Gerais: principais demandas para o desenvolvimento sustentável da atividade produtiva. In: Anais do SEMINÁRIO SOBRE ARRANJOS PRODUTIVOS DE BASE MINERAL. Brasília, DF: Ministério de Minas e Energia, 2003.

CLAVAL, P. A gênese das culturas. 3. ed. Florianópolis: Ed. UFSC, 2007.

COSGROVE, D.; DANIELS, S. (Ed.). The Iconography of landscape: essays on the symbolic representation, design, and use of past environments. Cambridge: Cambridge University Press, 2000.

D'AURIA, C. A. São Thomé das Letras na encruzilhada das fontes, dos tempos, e dos saberes: um estudo sobre etnografia e historicidade com registros audiovisuais. Dissertação (Mestrado) - IAR/Unicamp. Campinas: Brasil, 2000.

DOLLFUS, O. O espaço geográfico. Rio de Janeiro: Bertrand Brasil, 1991.

FERRETI, E. R. Turismo e Meio Ambiente: uma abordagem integrada. São Paulo: Roca, 2002.

FIGUEIREDO, A. M. L. A Função Turística do Patrimônio: questionamentos sobre a ideia de sustentabilidade do turismo cultural. Caderno Virtual de Turismo, v. 5, n. 4, p. 43-49, 2005.

FLEISCHER, D. I. R. São Thomé das Letras e Lagoa Santa: mineração, turismo e risco ao patrimônio histórico e natural. Revista Cadernos de Campo, p. 21-39, n. 14/15, 2006.

INSTITUTO BRASILEIRO DE GEOGRAFIA E ESTATÍSTICA. IBGE Cidades, 2017. Disponível em: https:// cidades.ibge.gov.br/brasil/mg/sao-thome-das-letras/panorama. Acesso em: 23 nov. 2017.

INSTITUTO DO PATRIMÔNIO HISTÓRICO E ARTÍSTICO NACIONAL. In: $\mathbf{1}^{\circ}$ Colóquio IberoAmericano de Paisagem cultural, patrimônio e projeto. Belo Horizonte, 2010. Disponível em: Acesso em: 09 dez. 2017.

LARAIA, R. B. Cultura. Um conceito antropológico. 19. ed. Rio de Janeiro: Zahar, 2003.

LIMA, M. O uso da entrevista na pesquisa empírica. In: Cebrap. Métodos de pesquisa em Ciências Sociais: bloco qualitativo. São Paulo: Sesc, 2016, p. 24-41.

PANOSSO NETTO, A. Segmentação do mercado turístico: estudos, produtos e perspectivas. São Paulo: Manole, 2009.

RICHARDSON, R. J. et al. Pesquisa social: método e técnicas. 3. ed. São Paulo: Atlas, 1999.

SANTOS, M. Pensando o espaço do homem. São Paulo: Hucitec, 1997.

TRIGO, L. G. G. A viagem: caminho e experiência. São Paulo: Aleph, 2013.

TUAN, Y. Topofilia: um estudo da percepção, atitudes e valores do meio ambiente. São Paulo: Difel, 1980.

URRY, J. O Olhar do Turista: lazer e viagens nas sociedades contemporâneas. São Paulo: Studio Nobel Sesc. 1996.

YIN, R. K. Estudo de caso: planejamento e métodos. 5. ed. Porto Alegre: Bookman, 2015. 


\section{Notas}

[1] O Barroco floresceu entre o final do século XVI e meados do século XVIII, inicialmente na Itália. Considerado como o estilo correspondente ao absolutismo e à contrarreforma, distingue-se pelo esplendor exuberante.

[2] Disponível em: http://www.visitesaothome.com.br/index.php?q=lendas. Acesso em: 28 de novembro de 2017.

\section{BY}

